\title{
HUMAN CAPABILITIES VERSUS HUMAN CAPITAL: GUAGING THE VALUE OF EDUCATION IN DEVELOPING COUNTRIES
}

(Accepted 24 June 2005)

\begin{abstract}
The purpose of this study is to defend the view that education should be evaluated in terms of the capability to achieve valued functionings, rather than mental satisfaction or resources. In keeping with Amartya Sen's capabilities approach we argue that mental satisfaction provides an inaccurate metric of well-being because of the phenomenon of adaptive preferences. Equally, resources cannot be used as a metric of well-being because of inequalities in the ability to convert income and commodities into valued functionings. Hence, interpreting education as a means to create human capital is also impoverished because it evaluates education solely in terms of the accumulation of resources. In order to provide evidence in support of the human capabilities approach we statistically examine the channels through which educational attainment affects the health functionings implied by life expectancy. Using panel data analysis for 35 developing countries for the years 1990, 1995 and 2000 we compare the health functionings (as indicated by life expectancy) that are achieved by the income growth generated by educational attainment, with the total health functionings that are achieved by educational attainment. We find that educational attainment (as indicated by average years of schooling) has a significant effect on life expectancy independently of its effect by way of income growth. A $1 \%$ increase in per capita income increases life expectancy by $0.073954 \%$, while a $1 \%$ increase in average years of schooling directly increases life expectancy by $0.055324 \%$. Because it shows that income underestimates the health functionings achieved by educational attainment, our empirical findings lend support to the claim that the value of education should be measured in terms of the capability for functioning, rather than resources.
\end{abstract}

KEY WORDS: capabilities approach, development, educational attainment, functionings, human capital, life expectancy, well-being

\section{INTRODUCTION}

Perhaps the standard way of gauging the value of education is to consider the per capita growth or individual incomes that are gener- 
ated because of it. ${ }^{1}$ Where the returns to education are expressed in terms of per capita income, however, we are left with a measure that is consistent with the possibility of a significant proportion of the population living in poverty. This can be rectified by focusing on the returns to education of those who are income deprived (e.g. the extent to which the average earnings increase of those who complete primary education is sufficient to elevate them above a pre-defined poverty line). Notice, however, that because they measure life quality in terms of resources - real income or commodity holdings - neither of these ways of formulating the returns to education requires that all children receive a basic education. Income deprivation, for instance, can be alleviated by relying on the fruits of growth trickling down or being redistributed to those who are living in poverty, rather than directly enhancing their personal earnings potential. That development strategy will be defended on the grounds that greater growth can be achieved whilst still mitigating resource deprivation. Hence, an optimizing resourcist approach will prioritize investment in the education of those segments of the population that are expected to contribute more to growth, such that resource deprivation is indirectly mitigated. For example, there may be greater productivity gains for society if the quality and length of schooling of those already completing the basic education cycle is prioritized (Behrman, 1990, pp. 35-36). Similarly, less may be invested in rectifying the educational attainment shortfall of girls if it is shown that doing so will not have a significant effect on growth (Barro, 1997, pp. 19-21).

One immediate problem with the resourcist approach to education is that there is no guarantee that the fruits of growth will actually end up benefiting those who are resource deprived. By contrast access to a basic education for all helps to ensure that the benefits of growth are widely shared. More fundamentally, and in keeping with the influential work of Amartya Sen (1985b), 1987, 1992, 1999), the resourcist approach entails an overly narrow metric of the value of education. For the foundational education capabilities that can be achieved as a result of completing a basic education - being able to read, write, count, communicate, argue, problem solve and so on - are the necessary preconditions for doing things and achieving results that we have reason to value. Namely, being able to plan one's life based on reasonable stable expectations, escape oppressive familial relations, avoid demeaning working conditions, effectively use health care 
services, enforce one's legal rights, engage more effectively in public debate and political decision-making and so forth.

If we gauge the value of education in terms of the capability to achieve valued functionings (human capabilities approach) rather than the accumulation of resources (human capital approach) it becomes clear that society is duty-bound to enable each child to complete at least a basic education, irrespective of their relative contributions to growth.

The feasibility of ensuring a basic education for all is shown by those countries that were able to do so during, or in spite of, economic growth. Thus, countries such as South Korea, Japan, Taiwan, Hong Kong, Thailand and post-reform China expanded access to education both before and during the process of growth. That is they did not wait until there was sufficient growth before expanding educational opportunities (Drèze and Sen, 1989, pp. 183-185 \& 193-197; Sen, 1999, pp. 41-46, 143-144; Drèze and Sen, 2002, p. 71). Economic growth clearly helps to facilitate the financing of education services; Nevertheless, some (at least previously) low-income countries such as Sri Lanka, Jamaica, pre-reform China, Costa Rica, Chile as well the Indian state of Kerala, have performed remarkably well in terms of improving literacy rates, life expectancy and mortality rates (Drèze and Sen, 1989, pp. 186-187; Sen, 1999, pp. 46-49, 90-91 \& 144; Drèze and Sen, 2002, pp. 71-72, 75-76).

In what follows we provide statistical evidence in support of the claim that the value of education should be measured in terms of the capability for functioning rather than the production of resources. Using panel data analysis for 35 developing countries we compare the health functionings (as indicated by life expectancy) that are achieved by the income growth generated by educational attainment with the total health functionings that are achieved by educational attainment. We find that educational attainment (as indicated by average years of schooling) has a significant effect on life expectancy independently of its effect by way of income growth. In other words if we accept that well-being should be gauged in terms of the functionings that can be achieved, then the human capital approach severely understates the value of education.

In the following section we examine the reasons for evaluating human well-being in terms of the capability for functioning as opposed to resources or welfare. Turning to the evaluation of education, 
we then further clarify the distinction between Amartya Sen's notion of human capabilities and the narrower notion of human capital. In the subsequent section we provide our rationale for gauging the value of education and resources in terms of the health functionings that are implied by life expectancy; namely being able to avoid escapable morbidity and premature mortality. Finally, we introduce the indicators of our explanatory variables, our empirical model and the results of our panel data analysis of 35 developing countries for the years 1990, 1995 and 2000.

\section{CAPABILITIES AND WELL-BEING}

It is typically assumed that the expansion of educational opportunities is crucial because it increases the resource holdings of the agent and the economic community in which she is participating. The primary alternative to resourcism in the literature is to gauge the quality of a person's life in terms of the achievement of what she subjectively judges is valuable for herself (i.e. welfare or utility). But there are significant problems with both the resourcist and welfarist conceptions of well-being which should lead us to rethink how we understand the relationship between education and development.

The problem with the welfarist metric of well-being is that individuals adapt what they hope to achieve according to what they perceive is feasible. Thus those who are brought up in deprived circumstances will, as a necessary survival strategy, tend to emphasize the small gains that come their way and downplay the significance of what they cannot hope to achieve and avoid (Elster, 1983: chap. III; Sen, 1985a, p. 191; 1985b, pp. 21-22, 29; 1987,11-12). In contrast those with privileged upbringings will require more resources in order to achieve their greater expectation horizon; resources that could otherwise be distributed to those who, through sheer ill luck, have experienced impoverished upbringings (Arrow, 1973, p. 254; Sen, 1985a, pp. 196-7). In sum, distributing according to welfare only serves to reflect and reinforce the unequal distribution of resources due to the social and economic circumstances that people are born into.

Because of the phenomenon of adaptive preferences the relevant focus must be the opportunities available to each person rather than their welfare achievements (Sen, 1992, pp. 31-33). The standard 
opportunity-based approach is to distribute resources (i.e. real income or commodities) such that each individual has the equal opportunity to pursue their aims and projects (for example, Rawls, 1971, pp. 92-95). Following Amartya Sen we reject the strictly resourcist approach on the grounds that people have differing abilities to convert resources into well-being (Sen, 1987, pp. 15-6; 1992, 27, 33). A person with a higher metabolic rate, for example, requires more food to be adequately nourished, a handicapped person can make less use of the same amount of income as an able-bodied person can and so on. The focus of attention therefore must be on what the person can actually do with the resources - their real income or commodity bundles - she possesses, rather than the resources in themselves.

What Sen suggests, therefore, is a metric of well-being that falls short of welfarism and yet is opportunity-based in a way that overcomes inequalities in the ability to convert resources. In other words a metric that is posterior of the possession of goods and prior to having mental satisfaction (i.e. welfare) (Sen, 1985b, p. 11). And so he proposes that we gauge how well a person's life is going in terms of the valued "doings" and "beings" she achieves, or functionings as he calls them. For example, avoiding escapable morbidity and mortality, being literate and numerate, being well nourished, taking part in the life of the community, possessing self-respect, being able to appear in public without shame, being sufficiently well informed and so on. Hence, a person's well-being is defined by the set of functionings she actually achieves.

The sets of combinations of functionings that a person can (if she so chooses) achieve, defines her capability to "do and be" (Sen, 1992, pp. 40, 50). The distinction between functionings and capabilities is crucial because of the instrumental and intrinsic value we associate with being left to choose for ourselves (Sen, 2002b, pp. 605-606 and 623-624). ${ }^{2}$ By way of illustration compare a rich person who is "fasting" with an impoverished person who cannot buy food. Both do not achieve the functioning of nourishment, but the former has the choice (Sen, 1992, pp. 40-41, 51-52). Similarly, rich conservative Muslim parents who withdraw their daughter from school at the age of puberty have the choice to expand her educational functionings, whereas impoverished parents, whether conservative or not, do not. 
The problem with gauging inequality and deprivation in terms of income should now be clear. Because of inequalities in the ability to convert resources into capabilities, income represents an inadequate measure of disparities in, and the deprivation of, the real opportunity to "do and be". The problem with the welfarist metric is even more pronounced because it only serves to reflect both inequalities in resources and in the ability to convert resources into valued functionings. Thus, for example, a person who is born into deprived circumstances and who has a high metabolic rate must adapt what she hopes to achieve according to both these forms of handicap.

In this paper we follow Sen and Jean Drèze in arguing that ensuring the capability for functioning constitutes the fundamental aim of development and therefore the fundamental reason for ensuring at least a basic education for all (Sen, 1999, pp. 36-37, 53; Drèze and Sen, 2002, p. 7). Hence incomes, and resources more generally, should be distributed so as to enable each person to avoid capability deprivation, not merely resource deprivation. For, according to that account of development, resources are merely instrumental to the achievement of the capability for functioning.

\section{HUMAN CAPITAL VERSUS HUMAN CAPABILITIES}

We take it that the government in each society is obligated, through the provision of educational opportunities, health care, basic rights and so on, to ensure that all at least have the basic capability to choose and pursue what they value in life (Nussbaum, 2000, pp. 6, 11; Alkire, 2002, chap. 5). However, in this paper we will be primarily concerned with the basic capability set that the provision of educational resources (i.e. teachers, classrooms, textbooks, teacher training, curriculum design etc) is able to bring about. The basic education capabilities encompasses those realized functionings such as being able to read, write, communicate, argue, count, calculate, practically reason (i.e. the ability to choose well amongst the bundles of functionings at one's disposal), possess a sense of self-worth, interact with others based on mutual respect, and so on that constitute the necessary (but not sufficient) preconditions for human agency - being able to choose and pursue one's goals and overall life-plan - and effective participation in the 
community's cooperative enterprise - political, social and productive agency.

The human capital approach to education differs significantly from the human capabilities approach because it focuses on the creation of productive agents (Sen, 1999, pp. 292-294). As a result, it measures the value of education in terms of the generation of aggregate resources and personal resources, including the ability to escape resource deprivation. That metric only encompasses one class of functionings that the basic education capabilities are a precondition of; namely, productive agency (being literate and numerate, for example, enables farmers to adopt more efficient production techniques in irrigation and fertilization). In other words, because it significantly narrows the set of valued functionings that education enables, the resourcism entailed by the human capital perspective provides us with a severely impoverished way of gauging the value of education.

Turning briefly from the basis for gauging the value of education to the setting of public policy we may ask whether the capability approach rules out the idea of delaying providing a basic education to some children because a higher level of economic growth can be achieved by investing limited public funds elsewhere (e.g. expanding and improving the quality of educational opportunities of those who are already able to complete a basic education). Even if those who are left educationally deprived do not as a result fall below the poverty line, that strategy is untenable once we measure the value of education in terms of the capability for functioning. Those children who achieve the basic functionings of reading and writing, for example, are more able to defend themselves in a court of law, obtain a bank loan, effectively use health care, read the newspaper and so on (Drèze and Sen, 2002, p. 143). Similarly, they are more able to escape from a domineering household relationship, avoid jobs where the working conditions are belittling, have some influence over political decision-making and therefore the way they are governed, and so on. Finally, education is also protective in the sense that improving female literacy levels constitutes the single best way to curb population growth and helps to reduce maternal, infant and child mortality rates (Sen, 1999, pp. 178-180; Siniscalco, 2001, pp. 9-11). In short, without the foundational educational capabilities a person's ability to protect themselves from ill-treatment and ill-health will be severely impaired. Crucially, that may remain the case in spite of the resource holdings at his or her disposal. 


\section{HEALTH FUNCTIONINGS AS A METRIC OF THE VALUE OF EDUCATION}

Even when education is interpreted narrowly as enabling the production of resources the target is the capability for functioning that those resources provide, not the resources per se (Sen, 1999, p. 295; Drèze and Sen, 2002, pp. 7, 81-82;). In other words, mere resource possession is even an inadequate measure of the value of human capital. Thus, for example, the appropriate basis for assessing whether access to a basic education enables the disadvantaged to escape deprivation is to consider whether the income and commodities they are able to accrue can be converted into other essential functionings, such as being able to avoid escapable morbidity and mortality.

With that in mind we set out to assess the claim that education should be evaluated in terms of the functionings that are achieved because of it (i.e. human capabilities approach), rather than the resources that are accumulated because of it (i.e. human capital approach). More precisely, we evaluate the educational functionings in terms of their ability to enable the health functionings of being able to avoid escapable morbidity and mortality (as indicated by life expectancy).

From Figure 1 we can see that there is a strong correlation between life expectancy and educational attainment (as indicated by average years of schooling) in developing countries (correlation coefficient $=0.8$ ).

While Figure 1 indicates an unambiguous relation between life expectancy and average schooling, further empirical analysis is required in order to test for causalities between these two indicators. Our primary concern here, therefore, is to determine exactly how it is that an increase in educational attainment extends life expectancy. To what extent is it due to the income growth that is generated by educational attainment? If it turns out that education has a significant income-independent effect on life expectancy, then income represents an impoverished metric of the value of education. That is to say, if we accept that life quality is defined by the capability for functioning, then it would be more accurate to measure education directly in terms of functionings such as those entailed by longevity.

We take the basic health functionings as our metric of the instrumental value of both education and income because they are essential 


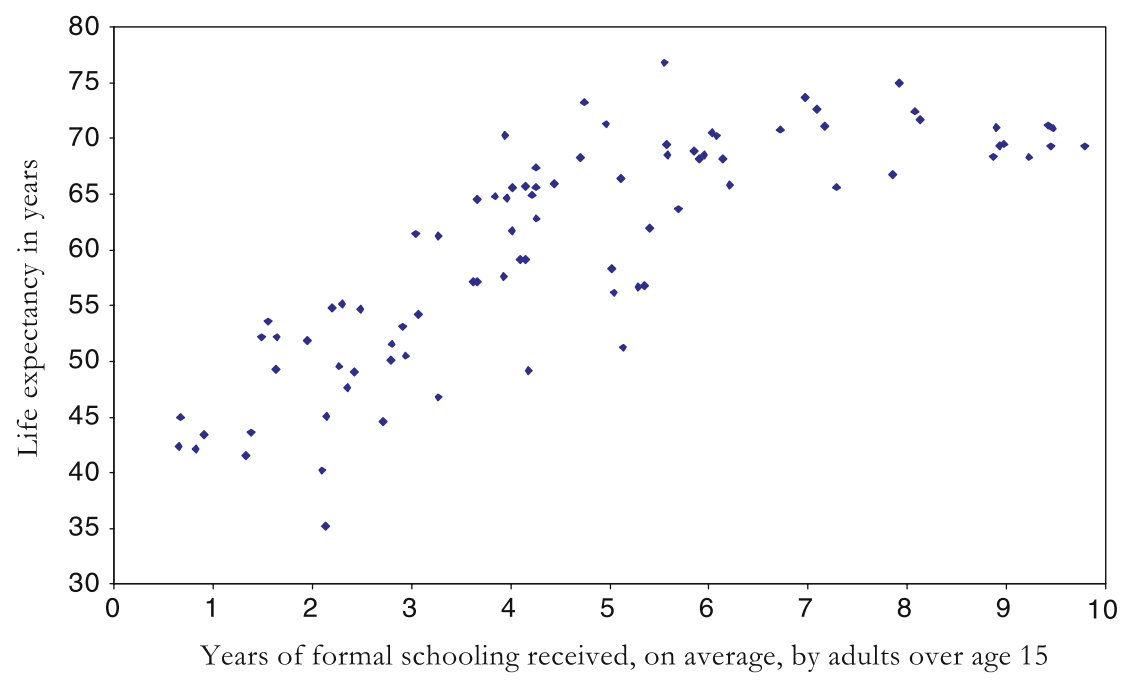

Figure 1. Life expectancy at birth and average years of schooling for 87 developing countries in 1990.

to ensuring the real opportunity to "do and be". Health functionings represent only a, albeit important, subset of the basic capabilities. Nevertheless, health data will to some extent reflect the presence or absence of the other basic functionings (e.g. being able to protect one's rights and being able to participate politically, being able to escape oppressive familial or workplace relations, a sense of self-respect etc). Indeed our analysis rests on the claim that there is a significant causal linkage between education and health. We take life expectancy at birth as our indicator of the basic health functionings because it encapsulates the avoidance of both preventable morbidity and premature mortality (including maternal, infant and child mortality). ${ }^{3}$ Moreover, longevity data is more reliable than morbidity data because the latter is typically based on subjective responses to questionnaires. Where there is widespread access to quality health care the perception of morbidity is actually higher than when there is limited exposure to health care (Sen, 1998, pp. 4-5 \& 17-20). In effect morbidity data is vulnerable to the adaptive preferences problem discussed above.

Education may have a positive effect on longevity either through income growth or in spite of income growth. In the first case, education may improve health indirectly because the micro- and macrolevel income growth that it generates may be used by the society or 
individual to prevent or treat ill health. Thus advocates of the human capital approach will produce evidence both that educational attainment is an important determinant of income growth, ${ }^{4}$ and that income is an important determinant of life expectancy.

In the second case, education may improve longevity independently of income growth. For example, as a result of improved access to education the individual is in a better position to access knowledge about their nutrition and health requirements, as well as how to use the public health care system. In addition there are psychosocial determinants of ill health, such as the stress induced by lack of self-respect and lack of control, that will be counteracted by an increase in educational attainment (Marmot, 2001, p. 745; Siegrist and Marmot, 2004). In the statistical analysis that follows we find that education has a significant effect on longevity via both these channels.

Because it tends to focus on average affluence the human capital approach leaves unspecified exactly how income growth increases longevity. To what extent is the income-mediated effect dependent on the distributional pattern of the income generated by education? Sudhir Anand and Martin Ravallion (1993) have found that the positive correlation between average income and life expectancy all but disappears once one controls for income poverty and public expenditure on health care. In other words, the positive effect of returns to education on life expectancy depends on the extent to which those returns alleviate poverty and the extent to which the government is willing to spend on health care. The upshot of this is that the income-mediated valuation of education should focus on the resulting distributional pattern, rather than average income. While lack of comparable poverty data prevents us from testing the relationship between income poverty and longevity we were able to test the relationship between public expenditure on health care and longevity.

\section{SPECIFICATION OF THE MODEL AND ESTIMATION RESULTS}

We now turn to clarify how we intend to compare the income-mediated and income-independent effects of education, and to present the results of that empirical analysis. 


\section{Explanatory Variables}

We take average years of schooling that are completed as our indicator of the basic educational functionings. ${ }^{5}$ Compared with literacy, attainment provides an indirect indicator of the capability for educational functioning. Nevertheless, it does allow us to observe the potential for functioning beyond the minimum measured by literacy rates. In addition, completion rates are a more reliable indicator of attainment than enrolment because school administrators may inflate the number of enrolments in order to obtain more funding from the government and students who enroll at the start of the academic year may not actually go on to attend school throughout that year (Barro and Lee, 1993, pp. 5-6). It is not really possible to interpret years of completed schooling as anything more than a rough indicator of educational functionings. For the extent to which each person can achieve those functionings hinges on the pedagogical quality of the curriculum, teachers, and instructional materials that they are presented with whilst they are at school. Having said that, educational attainment will at least in part reflect schooling quality because the latter is an important determinant of whether parents are willing to keep their children in school.

In the absence of comparable data we take GDP per capita as our indicator of income returns to education. ${ }^{6}$ Notice that because there are determinants of income growth, other than educational attainment (e.g. population trends, the level of trade openness, volatility of inflation, government expenditure on public infrastructures, political institutions etc), ${ }^{7}$ we bias the analysis in favor of the human capital approach by using average income as proxy for returns to education. Finally, public health expenditure is represented by the percentage of GDP that the government invests in health. ${ }^{8}$

\section{Model and Results}

For the quantitative analysis of the effects of education on capability development, a life expectancy (LE) equation is estimated. The data set used for estimation is a panel of 35 low and middle income countries for the years 1990, 1995 and $2000 .^{9}$

$$
\mathrm{LE}=\beta_{0}+\beta_{1} \mathrm{AS}+\beta_{2} \mathrm{GDP}+\beta_{3} \mathrm{HE}
$$


In the first equation, the dependent variable life expectancy (LE) represents health functionings. The explanatory variable representing educational functionings is average schooling (AS). The other explanatory variable, health expenditure (HE) is chosen to obtain the effect of health expenditure on life expectancy. The HE variable also enables us determine the extent to which the effect of income depends on its distributional pattern. The last explanatory variable is GDP per capita (GDP).

In the estimation process, the fixed effect specification of the panel data is used to account for time-invariant unobservable heterogeneity among countries that is potentially correlated with the dependent variable. In so doing, we also dispense with the omitted-variable problems in the regressions, by means of capturing idiosyncratic factors that might have affected life expectancy in the sample countries.

Before exploring the quantitative relationship between the explanatory variables and the dependent variables, one has to take into account the relationship between AS and GDP variables. The nature of the interactions between the AS and GDP variables might reveal that the AS variable exerts no influence on life expectancy other than by way of GDP per capita. So it is important for our thesis to investigate whether the effect of AS on LE works in two ways, namely; the direct effect, and the indirect effect via GDP per capita. To that end, equations (2) and (3) are estimated:

$$
\begin{aligned}
& \mathrm{LE}=\beta_{0}+\beta_{1} \mathrm{GDP} \\
& \mathrm{LE}=\beta_{0}+\beta_{1} \mathrm{GDP}+\beta_{2} \mathrm{AS}
\end{aligned}
$$

Table 1 summarizes the estimation outcomes of the above equations.

From Table I, one can see that the GDP variable parameter has a positive sign and is statistical significant at the $10 \%$ significance level in the equation (2) estimation. In equation (3) AS is included in the LE estimation. As can be seen from Table I, AS has a positive and statistically significant effect on LE, indicating a direct positive relation between AS and LE in addition to the indirect effect via GDP per capita. Hence, it is justified to include AS variable in Equation (1) since they have an independent influence on LE. ${ }^{10}$

Table II gives the fixed effect estimation results of the LE equation. ${ }^{11}$ With the explanatory variables all being statistically signifi- 
TABLE I

Estimation Results of Equation (2) and (3)

\begin{tabular}{|c|c|c|c|c|}
\hline Variable & Coefficient & Std. Error & $t$-Statistic & Prob. \\
\hline \multicolumn{5}{|l|}{ Equation (2) } \\
\hline $\mathrm{C}$ & 1.512623 & 0.160971 & 9.396841 & 0.0000 \\
\hline GDP & 0.083485 & 0.047953 & 1.740982 & 0.0913 \\
\hline $\operatorname{AR}(2)$ & 1.447245 & 0.246922 & 5.861149 & 0.0000 \\
\hline$R$-squared & 0.826117 & \multicolumn{2}{|c|}{ Mean dependent var } & 1.827371 \\
\hline Adjusted $R$-squared & 0.815249 & \multicolumn{2}{|c|}{ SD dependent var } & 0.068374 \\
\hline S.E. of regression & 0.029389 & \multicolumn{2}{|c|}{ Sum squared resid } & 0.027639 \\
\hline$F$-statistic & 76.01581 & \multicolumn{2}{|c|}{$\operatorname{Prob}(F$-statistic $)$} & 0.000000 \\
\hline \multicolumn{5}{|l|}{ Equation (3) } \\
\hline $\mathrm{C}$ & 1.502908 & 0.131022 & 11.47067 & 0.0000 \\
\hline GDP & 0.070719 & 0.040580 & 1.742713 & 0.0913 \\
\hline AS & 0.089039 & 0.051499 & 1.728940 & 0.0938 \\
\hline $\operatorname{AR}(2)$ & 1.558927 & 0.258111 & 6.039757 & 0.0000 \\
\hline$R$-squared & 0.837108 & \multicolumn{2}{|c|}{ Mean dependent var } & 1.827371 \\
\hline Adjusted $R$-squared & 0.821345 & \multicolumn{2}{|c|}{ SD dependent var } & 0.068374 \\
\hline S.E. of regression & 0.028900 & \multicolumn{2}{|c|}{ Sum squared resid } & 0.025892 \\
\hline$F$-statistic & 53.10357 & \multicolumn{2}{|c|}{$\operatorname{Prob}(F$-statistic $)$} & 0.000000 \\
\hline
\end{tabular}

*Estimation method is pooled least squares. Standard errors and t-statistics of coefficients are computed using White's heteroscedasticity consistent variancecovariance estimator. The $\mathrm{AR}(2)$ term is also included in the equation estimation because of the detected autocorrelation problem during the estimation process. The equation is estimated in $\log$ form.

TABLE II

Results of Life Expectancy Equation Estimation

\begin{tabular}{lllll}
\hline Variable & Coefficient & Std. Error & $t$-Statistic & Prob. \\
\hline GDP & 0.073954 & 0.001459 & 50.69688 & 0.0000 \\
AS & 0.055324 & 0.002789 & 19.83732 & 0.0000 \\
HE & 0.025893 & 0.000563 & 45.96303 & 0.0000 \\
$R$-squared & 0.999999 & Mean dependent var & 7.743993 \\
Adjusted $R$-squared & 0.999998 & SD dependent var & 9.706263 \\
S.E. of regression & 0.014555 & Sum squared resid & 0.013982 \\
$F$-statistic & 22902015 & Durbin-Watson stat & 2.070060 \\
Prob $F$-statistic) & 0.000000 & & \\
\hline
\end{tabular}

*Estimation method is GLS (cross section weights). Standard errors and $t$-statistics of coefficients are computed using White's heteroscedasticity consistent variance-covariance estimator. Country specific fixed effects are not reported. The equation is estimated in log form. 
cant, one can conclude that average schooling, health expenditure and per capita income do affect life expectancy in developing countries. According to the LE equation estimation, and in line with the theoretical expectation, the parameter of AS has a positive sign indicating that a $1 \%$ increase in AS increases life expectancy by $0.055324 \%$. Remembering that the AS variable has an independent effect on GDP per capita (estimation results of Equation 3 in Table I), the coefficient of the AS shows the direct effect of education on longevity. One is also able to see from Table II, that the parameter estimate of GDP per capita has, as expected, a positive sign. Hence, a $1 \%$ increase in GDP per capita increases life expectancy by $0.073954 \%$. We should remember, however, that that figure overstates the income-mediated effect of education because there are determinants of per capita income other than educational attainment. Once we take that fact into account it appears that the incomeindependent effect is at least commensurate with the incomemediated effect.

We can conclude, therefore, that income per capita denotes an impoverished metric of the value of education because educational attainment has significant effect on longevity independently of the income that is accumulated because of it. In other words, health functionings such as those entailed by life expectancy provide a more inclusive gauge of the value of education than per capita income.

In addition, the outcomes of the equation (1) estimation show that health expenditure is a significant variable with a positive sign in the LE equation. That is to say, a $1 \%$ increase in HE increases life expectancy by $0.025893 \%$. Thus, in keeping with the conclusions of Anand and Ravallion, the way in which the fruits of growth are spent by each government is also an important determinant of life expectancy. Note, however, that the income-independent effect of AS is significantly greater than that of HE. What is more the income-independent effect of AS in combination with the effect of HE is greater than that of GDP per capita. In other words, our analysis strongly supports the view that the public provisioning of education and health care should take place even when doing so will generate no, or little, income growth. Moreover, as we have already noted, evidence from a number of, at least previously, low income countries shows that it is feasible to publicly invest in health and education during, or in spite of, economic growth (Mehrotra, 1998). 


\section{CONCLUSION}

In this paper we have argued that education should be evaluated in terms of the capability to achieve valued functionings, rather than in terms of mental satisfaction or resources. Mental satisfaction provides an inaccurate guide to well-being because we adapt our preferences according to the expectation horizon defined by the circumstances in which we are born and raised. Resources only have value insofar as they enable a person to convert them into valued functionings. Hence, inequalities in the ability to convert resources into valued "doings" and "beings", means that income and commodities cannot be used to gauge well-being. Similarly, we have argued, the human capital approach is impoverished because it restricts its valuation of education to the accumulation of resources.

In order to defend the human capabilities approach against the human capital approach we have examined the channels through which educational attainment affects the health functionings entailed by life expectancy. The upshot of our panel data analysis is that the set of functionings enabled by educational attainment - being able to read, count, communicate, make informed choices, have a sense of selfworth, have greater degree of control over one's life and so on - have a substantial impact on life expectancy. Significantly, the direct effect of those educational functionings on longevity is almost equivalent to their effect by way of resource accumulation. We found that a $1 \%$ increase in per capita income increases life expectancy by $0.073954 \%$, while a $1 \%$ increase in average years of schooling directly increases life expectancy by $0.055324 \%$. Hence, the improvement of health awareness and the pyschosocial environment that is brought about by increases in educational attainment appear to play a significant role in determining longevity in developing countries. That result is even more revealing given that GDP per capita overstates income growth due to educational attainment and, therefore, the income-mediated effect of education on life expectancy. Because it shows that average income underestimates the health functionings achieved by educational attainment, our empirical analysis serves to support the claim that education should be measured in terms of the capability for functioning, rather than resources. What is more, that metric provides reason for the public provisioning of education even when doing so will not have a significant effect on income growth. 


\section{NOTES}

${ }^{1}$ See for example OECD (2003, pp. 156-176) and OECD/UNESCO (2002, chap. (1). For a recent overview of the extensive literature on returns to education see Psacharopoulos and Patrinos (2002).

${ }^{2}$ For a detailed discussion of the value we associate with having what happens to us depend on how we ourselves choose see Scanlon (1988, pp. 177ff).

${ }^{3}$ Life expectancy at birth is the number of years a newborn infant would live if prevailing patterns of mortality at the time of its birth were to stay the same throughout its life. Data source: World Bank, World Development Indicators 2005.

${ }^{4}$ A recent study of 16 developing countries, for example, found that an increase of average schooling by one year leads to a $3.7 \%$ increase in the long term economic growth rate (OECD/UNESCO, 2002: 32).

${ }^{5}$ Years of formal schooling received, on average, by adults over age 15. Data source: Barro and Lee, 2000.

${ }^{6}$ GDP is converted into international dollars using purchasing power parity rates. Data are in constant 2000 international dollars. Data source: World Bank, World Development Indicators, 2005.

${ }^{7}$ For a comparison of the various determinants of growth see Barro, 2002 and OECD/UNESCO, 2002, chap. 1.

${ }^{8}$ Data source: UN Human Development Reports for 2004 table 19, 2003 table 6, and 1999 table 13.

${ }^{9}$ Argentina, Bangladesh, Bolivia, Brazil, Chile, China, Columbia, Costa Rica, Dominican Republic, Ecuador, Egypt, El Salvador, Ghana, Honduras, Hungary, Indonesia, Iran, Jamaica, Malaysia, Mexico, Nicaragua, Pakistan, Panama, Paraguay, Peru, Philippines, Poland, South Africa, Sri Lanka, Thailand, Tunisia, Uganda, Uruguay, Venezuela, Zambia. These are low and middle income countries as defined by the World Bank.

${ }^{10}$ Multicollinearity is tested by calculating simple correlation coefficients as well as running the auxillary regressions between GDP and AS variables and GDP and HE variables. Outcomes of those multicollinearity tests indicate no level of harmful colinearity between the variables.

${ }^{11}$ Before the fixed effect model estimation, and in order to test for behavioral differences among countries, the $F$ test was performed. That test supports the presence of country differences. Accordingly, the fixed effect model estimation was performed by assuming time invariant differences among cross section units in terms of the intercepts.

\section{REFERENCES}

Alkire, S.: 2002, Valuing Freedoms: Sen's Capability Approach and Poverty Reduction (Oxford University Press, Oxford).

Anand, S. and Ravallion, M.: 1993, Human development in poor countries: On the role of private incomes and Public Services, Journal of Economic Perspectives 7, pp. $133-150$.

Arrow, K.J.: 1973, Some ordinalist-utilitarian notes on Rawls's Theory of Justice, The Journal of Philosophy 70, pp. 245-263. 
Barro, R.J.: 1997, Determinants of Economic Growth: A Cross-Country Empirical Study (MIT Press, Cambridge MA).

Barro, J.: 2002, Education as a determinant of economic growth, in E.P. Lazear (ed.), Education in the Twenty-First Century (Hoover Institution Press, Stanford), pp. 9-24.

Barro, R.J. and J.-W. Lee: 1993, 'International comparisons of educational attainment', NBER Working Paper No. w4349.

Barro, R.J. and J.-W. Lee: 2000, 'International Data on Educational Attainment: Updates and Implications', (CID Working Paper no. 42) at www.cid.harvard.edu/ ciddata/ciddata.html.

Behrman, J.R.: 1990, The Action of Human Resources and Poverty on One Another: What We Have Yet to Learn LSMS Working Paper No. 74 (World Bank, Washington DC).

Drèze, J. and A. Sen: 1989, Hunger and Public Action (Oxford University Press, Oxford).

Drèze, J. and A. Sen: 2002, India: Development and Participation (Oxford University Press, Oxford).

Elster, J.: 1983, Sour Grapes: Studies in the Subversion of Rationality (Cambridge University Press, Cambridge).

Marmot, M.: 2001, Sustainable development and the social gradient in coronary heart disease, European Heart Journal 22, pp. 740-750.

Mehrotra, S.: 1998, Education for All: Policy Lessons from High-Achieving Countries. UNICEF Staff Working Papers, no. EPP-EVL-98-005 (UNICEF, Geneva).

Nussbaum, M.: 2000, Women and Human Development: The Capabilities Approach (Cambridge University Press, Cambridge).

OECD: 2003, Education at a Glance, 2003 Editions (OECD, Paris).

OECD/UNESCO: 2002, Financing Education: Investments and Returns: Analysis of the World Education Indicators (OECD, Paris).

Psacharopoulos, G. and H. Patrinos: 2002, 'Returns to Investment in Education: A Further Update' Policy Research Working Paper WPS2881 (World Bank, Washington DC).

Rawls, J.: 1971, A Theory of Justice (Harvard University Press, Cambridge MA).

Scanlon, T.M.: 1988, The Significance of Choice, in S.M. McMurrin (ed.), The Tanner Lectures on Human Values Vol. VIII (University of Utah Press, Salt Lake City).

Sen, A.: 1985a, Well-Being, agency and freedom: The Dewey Lectures 1984, The Journal of Philosophy 82, pp. 169-221.

Sen, A.: 1985b, Commodities and Capabilities (North Holland, Amsterdam).

Sen, A.: 1987, The Standard of Living (Cambridge University Press, Cambridge).

Sen, A.: 1992, Inequality Reexamined (Harvard University Press, Cambridge MA).

Sen, A.: 1998, Mortality as an indicator of economic success and failure, The Economic Journal 108, pp. 1-25.

Sen, A.: 1999, Development as Freedom (Anchor Books, New York).

Siegrist, J. and M. Marmot: 2004, Health Inequalities and the Pyschosocial Environment - Two Scientific Challenges, Social Science and Medicine 58, pp. 14631473.

Siniscalco, M.T.: 2001, Achieving Education for All: Demographic Challenges (UNESCO, Paris). 
UNDP: 2004, Human Development Report (UNDP, New York).

UNDP: 2003, Human Development Report (UNDP, New York).

UNDP: 1999, Human Development Report (UNDP, New York).

World Bank: 2005, World Development Indicators (World Bank, Washington DC).

Department of Philosophy

Simon Wigley

Faculty of Humanities and Letters

Bilkent University

Bilkent, Ankara 06800

Turkey

E-mail: wigley@bilkent.edu.tr

Department of Economics

Arzu Akkoyunlu-Wigley

Hacettepe University

Turkey

E-mail:arzus@hacettepe.edu.tv 